\title{
Aprotinin does not decrease early graft patency after coronary artery bypass grafting despite reducing postoperative bleeding and use of donated blood
}

Forty-five male patients with planned coronary artery bypass operation were randomized in a double blind fashion to receive either 6 million kallikrein inactivator units of aprotinin (high-dose group), 2 million kallikrein inactivator units of aprotinin (low-dose group), or placebo (control group). Postoperative bleeding was significantly decreased in both aprotinin groups in comparison to that in the control group $(590 \mathrm{ml}$ [ 290 to $1800 \mathrm{ml}$ ] high-dose group and $650 \mathrm{ml}$ [280 to $1900 \mathrm{ml}$ low-dose group versus $920 \mathrm{ml}$ ( 350 to $2700 \mathrm{ml}$ ) control group, $p<0.001$ ). There was no difference between the two aprotinin groups. The need for postoperative blood transfusion was significantly lower in the aprotinin groups (1.46 [0 to 4] blood units high-dose group and 1.65 [0 to 5] blood units low-dose group versus 2.43 [0 to 7] blood units control group, $p<0.05$ ). All patients underwent coronary angiography between the seventh and twelfth postoperative day. No difference was found among the three groups in patency of vein grafts-93.8\% in the high-dose group, $94.5 \%$ in the low-dose groups, and $93.3 \%$ in the control group. Therefore, aprotinin significantly reduced postoperative bleeding and transfusion requirement after coronary artery bypass grafting without influencing early graft patency. (J THORAC CARDIOVASC SURG 1994;107:807-10)

Michael Havel, MD, Florian Grabenwöger, MD, Johannes Schneider, MD, Günter Laufer, MD, Gregor Wollenek, MD, Alyson Owen, MD, Paul Simon, MD, Harald Teufelsbauer, MD, and Ernst Wolner, MD, Vienna, Austria

$\mathrm{T}$ he use of the proteinase inhibitor aprotinin during cardiac operations requiring extracorporeal circulation can lead to a significant reduction in postoperative bleeding and transfusion requirements. These phenomena were first described in 1987 by Royston and colleagues. ${ }^{1}$ Many other groups confirmed the blood-sparing action of aprotinin after cardiac operations. ${ }^{2-5}$ In Western Europe, aprotinin is used routinely in many cardiac surgery centers.

The mechanism of action of aprotinin has largely been explained. Van Oeveren and colleagues ${ }^{6}$ reported a protective effect of aprotinin on platelet factor glycoprotein

From the Second Department of Surgery, University Hospital of Vienna, Vienna, Austria.

Received for publication Feb. 2, 1993.

Accepted for publication July 30, 1993.

Address for reprints: Michael Havel, MD, Second Department of Surgery, University of Vienna, Spitalgass 23, A-1090 Wien, Austria

Copyright $\odot 1994$ by Mosby-Year Book, Inc.

$0022-5223 / 94 \$ 3.00+0 \quad \mathbf{1 2 / 1 / 5 0 4 6 7}$ $\mathrm{lb}$ during the contact of the platelets with the artificial surface of the extracorporeal circulation system. We were able to demonstrate that aprotinin led to an enhancement of intravascular coagulation while simultaneously inhibiting fibrinolysis. ${ }^{7}$ Further, it could be observed that in human endothelial cells incubated with different concentrations of aprotinin significantly more von Willebrand factor (factor VIII) and thromboxane $B_{2}$ were produced, and the release of 6-keto-prostaglandin $\mathrm{F}_{1 \alpha}$ was reduced ${ }^{8,9}$ From these observations, it could be suggested that the use of aprotinin during coronary artery bypass operations would lead to greater intravascular coagulation and theoretically to a higher early graft occlusion rate.

In the present study, patients who had received aprotinin or placebo during coronary artery bypass operation in a double-blind randomized trial underwent coronary angiography 7 to 12 days after the operation. The goal of the study was to investigate whether the use of aprotinin during coronary artery bypass operation would lead to an increased graft occlusion rate. 
Table I. Demographic data

\begin{tabular}{lccc}
\hline & $\begin{array}{c}\text { High-dose } \\
\text { aprotinin } \\
(\mathrm{n}=15)\end{array}$ & $\begin{array}{c}\text { Low-dose } \\
\text { aprotinin } \\
(\mathrm{n}=15)\end{array}$ & $\begin{array}{c}\text { Placebo } \\
(\mathrm{n}=15)\end{array}$ \\
\hline Age (yr) & $60 \pm 8$ & $59 \pm 8$ & $60 \pm 9$ \\
Weight (kg) & $79 \pm 11$ & $79 \pm 10$ & $79 \pm 8$ \\
Height (cm) & $174 \pm 7$ & $171 \pm 5$ & $173 \pm 6$ \\
Smoker (\%) & 54 & 59 & 57 \\
Hypertension (\%) & 42 & 40 & 44 \\
Ejection fraction (\%) & 39 & 42 & 41 \\
\hline
\end{tabular}

\section{Patients and methods}

Study population. After receiving full explanation and giving informed consent, 45 male patients undergoing routine coronary artery bypass operation were randomized to receive either high-dose or low-dose aprotinin or placebo. The following were exclusion criteria: second operation, emergency operation, congenital or acquired thrombopathy, medications with an influence on platelet function taken within 7 days before operation, left ventricular ejection fraction less than $33 \%$, end-diastolic pressure greater than $20 \mathrm{~mm} \mathrm{Hg}$, patient age greater than 70 years, and single vessel coronary disease.

Study medication. The patients in the high-dose aprotinin group received 2.0 million kallikrein inactivator units (KIU) as a bolus (over 30 minutes) after the institution of anesthesia but before skin incision, 2.0 million KIU as a continuous infusion (over 4 hours), and 2.0 million KIU in the heart-lung machine. The patients in the low-dose aprotinin group received only 2.0 million KIU in the heart-lung machine.

The patients in the control group received $0.9 \%$ saline solution as a placebo. The study preparation consisted of a short infusion bottle with $70 \mathrm{mg}$ aprotinin (equal to $500,000 \mathrm{KIU}$ ) in $50 \mathrm{ml}$ of $0.9 \%$ saline solution without other additives or preservatives. The corresponding placebo contained only physiologic saline solution. Bottles of placebo and bottles of $70 \mathrm{mg}$ of aprotinin in $50 \mathrm{ml}$ of $0.9 \%$ saline solution were not distinguishable from each other.

The preparation for each patient was individually packaged with 12 bottles each; each individual bottle, as well as the carton, was marked with a label carrying the patient number (the randomization number). Each study package contained a total of 12 bottles, of which eight carried the label "Infusion" and four the label "Pump". These additional labels described whether the bottle was to be used for the initial bolus infusion, for the continuous infusion, or as an addition to the filling volume of the heart-lung machine.

In the high-dose aprotinin group, all 12 bottles contained aprotinin. In the low-dose group, all bottles with the label "Infusion" contained placebo, with only the bottles labeled "Pump" containing aprotinin. In the control group, all 12 bottles contained placebo. The randomization was carried out as a block randomization; the order was strictly maintained, and the code was broken only at the completion of the study.

Extracorporeal circulation and operative procedure. The coronary artery bypass operation was carried out in the standard fashion of our institution with the use of membrane oxygenators during cardiopulmonary bypass. Myocardial protection was accomplished with multiple-dose blood cardioplegic solution $\left(5^{\circ}\right.$ to $\left.7^{\circ} \mathrm{C}\right)$ and systemic hypothermia of $28^{\circ}$ to $29^{\circ} \mathrm{C}$. The saphenous vein was carefully harvested, gently distended with heparinized $0.9 \%$ saline solution, and stored in blood until implantation. The internal mammary artery was used for revascularization of the left anterior descending artery in all cases. The distal anastomoses were performed with 7-0 Prolene sutures (Ethicon, Inc., Somerville, N.J.). The proximal anastamoses were performed during the reperfusion phase with 6-0 Prolene sutures (Ethicon). Grafts were constructed as either single or sequential grafts. Coronary endarterectomy was performed in diffusely diseased native arteries at the discretion of the surgeon. Coronary artery diameter at the point of anastamosis was measured with calibrated probes. The patients were heparinized according to their body weight. An activated clotting time of more than 400 seconds was maintained during the entire bypass time. At the end of extracorporeal circulation, the heparin was antagonized with protamine sulfate.

Transfusion requirements during and after operation were tabulated for each patient, and chest tube blood loss was measured and recorded hourly until removal of all drains. Technical aspects of the perfusion, bypass and crossclamp times, postoperative support, and complications were recorded.

Graft angiography. All angiograms were performed by the same investigator 7 to 12 days after the operation. The investigations were performed with the transfemoral Judkins technique. Selective contrast injection in all vein and internal mammary grafts was carried out. In those cases in which a selective injection in the graft was not possible, a biplane aortic root angiogram was done. All angiograms were evaluated by two experienced cardiologists, who were blinded to the intraoperative medication received. A graft was classified as patent if contrast was seen to flow through the graft into the distal native coronary artery. A distal anastamosis was defined as patent (in single or sequential grafts) if contrast was seen to flow into the grafted artery.

Statistical analysis. For the description of data, means or medians, standard deviations or ranges, and cell frequencies or percentages of cross-tabulation tables were calculated. General association of nominal or ordinal data was tested by Fisher's exact test. For tables larger than $2 \times 2$, the network algorithm given by Metha and Patel was used. The null hypothesis was independence, and the alternative hypothesis was general association. For continuous data, the Mann-Whitney test was used for evaluating group differences in medians. The significance level was set to be less than 0.05 . All calculations were performed with SAS statistical software. ${ }^{10}$

\section{Results}

Patients. The demographic data of the study patients are displayed in Table I. No differences were found between the groups in patient age, height, weight, risk factors for coronary disease, ejection fraction, or previous infarctions. Similarly, no differences were found in the number of distal anastamoses, the number of endarterectomies, extracorporeal circulation, aortic crossclamp time, or timepoint of coronary angiography (Table II).

Postoperative blood loss and transfusion requirement. Significantly reduced postoperative blood loss up to the time point of drain removal was found in both the high-dose and low-dose aprotinin groups in comparison 
Table II. Perioperative data

\begin{tabular}{lccc}
\hline & $\begin{array}{c}\text { High-dose } \\
\text { aprotinin } \\
(\mathrm{n}=15)\end{array}$ & $\begin{array}{c}\text { Low-dose } \\
\text { aprotinin } \\
(\mathrm{n}=15)\end{array}$ & $\begin{array}{c}\text { Placebo } \\
(\mathrm{n}=15)\end{array}$ \\
\hline Distal anastomoses (per patient) & 3.6 & 3.8 & 3.7 \\
Total vein anastomoses & 39 & 42 & 40 \\
ECC time (min) & $90 \pm 26$ & $89 \pm 27$ & $92 \pm 23$ \\
ACC time (min) & $41 \pm 12$ & $45 \pm 14$ & $43 \pm 16$ \\
Time point of angiography & $7 \pm 2$ & $7 \pm 1$ & $7 \pm 3$ \\
$\quad$ (days postop) & & & \\
\hline
\end{tabular}

$E C C$, Extracorporeal circulation; $A C C$, aortic crossclamp; postop, after the operation.

with that in the control group $(p<0.001)$. No significant difference was seen between the two aprotinin groups. (Table III). Similarly, the transfusion requirement was significantly lower in the high-dose and low-dose aprotinin groups than that in the control group, again, with no difference found between the two aprotinin groups (Table IV).

Graft patency. The left anterior descending artery was revascularized with the left internal mammary artery in all cases. All mammary anastamoses were found to be open at angiography. The vein graft patency rate (by distal anastamosis) was 93.8 in the high-dose Aprotinin group, 94.5 in the low-dose group, and 93.3 in the control group. No significant difference was found in patency rate among the three groups.

\section{Discussion}

Royston and colleagues ${ }^{1}$ were the first to demonstrate that the use of the proteinase inhibitor aprotinin led to significant reduction in postoperative bleeding after cardiac reoperations. The mechanisms of the blood-sparing effect of aprotinin have been largely explained. $2,3,7$ Aprotinin inhibits the endothelial synthesis of 6-ketoprostaglandin $F_{1 \alpha}$ (prostacyclin) and simultaneously stimulates the synthesis and release of thromboxane $B_{2}$, leading to enhancement of thrombocyte aggregation. ${ }^{8}$ Simultaneously, aprotinin results in an increased synthesis and release of von Willebrand factor from the human endothelial cells, mediating platelet adhesion to the subendothelium. ${ }^{9}$ Furthermore, we were able to show that aprotinin used during and after extracorporeal circulation led to a significant reduction in the concentrations of cross-linked fibrin degradation products, suggesting that aprotinin results in an inhibition of intravascular fibrinolysis. ${ }^{7}$

From these demonstrated actions of aprotinin, the theoretical concern arises that the use of aprotinin would lead not only to a reduction of postoperative bleeding but could also lead to increased intravascular coagulation. Because
Table III. Postoperative blood loss

\begin{tabular}{lccc}
\hline \multicolumn{1}{c}{ Group } & $\begin{array}{c}\text { No. of } \\
\text { patients }\end{array}$ & $\begin{array}{c}\text { Mean blood loss } \\
\text { (range) }\end{array}$ \\
\hline in millititers & p Value \\
Low-dose aprotinin & 15 & $590(290-1800)$ & $<0.001$ \\
Placebo & 15 & $650(280-1900)$ & $<0.001$ \\
\hline
\end{tabular}

Table IV. Postoperative transfusion requirements

\begin{tabular}{|c|c|c|c|}
\hline Group & $\begin{array}{c}\text { No. of } \\
\text { patients }\end{array}$ & $\begin{array}{c}\text { Mean transfusion } \\
\text { requirement } \\
\text { (range) } \\
\text { in blood units }\end{array}$ & $\mathrm{p}$ Value \\
\hline High-dose aprotinin & 15 & $1.46(0-4)$ & $<0.05$ \\
\hline Low-dose aprotinin & 15 & $1.65(0-5)$ & $<0.05$ \\
\hline Placebo & 15 & $2.43(0-7)$ & - \\
\hline
\end{tabular}

this would have special implications in the area of coronary artery bypass operations, the goal of this study was to investigate whether the use of aprotinin led to a higher rate of early graft occlusion after coronary bypass operations.

We explored the question of whether the dose-dependent effect demonstrated in human endothelial cell cultures was clinically relevant or if one could achieve the same reduction in postoperative bleeding with a reduced dose of aprotinin.

This study demonstrated that no increase in early graft occlusion was observed after either low- or high-dose aprotinin therapy. At perioperative angiography performed 7 to 12 days after the operation, all internal mammary grafts were open. No significant differences in the patency rate for venous anastamoses were seen among the study groups $(93.8 \%$ in the high-dose aprotinin group, $94.5 \%$ in the low-dose group, and $93.3 \%$ in the control group). These data imply that the therapeutic window for aprotinin is large; that is, the clinical benefit is achieved at much lower doses than those required to promote thrombotic graft occlusion, as no decrease in graft patency was observed even in the high-dose aprotinin group. Further, the effect of aprotinin on the reduction of postoperative bleeding and decrease in transfusion requirements was again confirmed. A significant reduction in postoperative bleeding was seen in both the high- and low-dose aprotinin regimen group in comparison with that in the control group. Importantly, no significant difference was seen in the amount of postoperative blood loss between the aprotinin groups.

These results contradict those from our in vitro work, which demonstrated that the effects on prostacyclin, 
thromboxane, and von Willebrand factor synthesis were dose dependent. According to the present study, the addition of only 2 million KIU of aprotinin to the priming volume of the heart-lung machine was enough to reach the same postoperative bleeding that has been reached in other studies by much higher doses of aprotinin. $^{3}$

In summary, it can be said that the use of aprotinin leads to a significant reduction in postoperative bleeding after cardiac operations. The minimal aprotinin dosage at which this effect can be reached requires further investigation because of commercial considerations. The theoretical concern that aprotinin, through its effect on the coagulation system, could lead to a higher graft occlusion rate after coronary artery bypass operation was not supported by our results.

\section{REFERENCES}

1. Royston D, Taylor KM, Bidstrup BP, Sapsford RN. Effect of aprotinin on need for blood transfusion after repeated open-heart surgery. Lancet 1987;1:1289-91.

2. Havel M, Owen A, Simon P, et al. Decreasing use of donated blood and reduction of postoperative bleeding after orthotopic heart transplantation by using aprotinin. $\mathrm{J}$ Heart Lung Transplant [In press].

3. Bidstrup B, Royston D, Sapsford R, Taylor K. Reduction in blood loss and blood use after cardiopulmonary bypass with high dose aprotinin. J THORAC CARDIOvasc SuRg 1989;97:364-72.

4. van Oeveren W, Jansen NJG, Bidstrup B. Effects of Aprotinin on hemostatic mechanisms during cardiopulmonary bypass. Ann Thorac Surg 19487;640-5.

5. van Oeveren W, Harder MP, Roozendaal KJ, Eijsman L, Wildevuur $\mathrm{CR}$. Aprotinin protects platelets against the initial effect of cardiopulmonary bypass. J THORAC CARDIOVASC SURG 1990;99:788-97.

6. van Oeveren W, Eijsman L, Roozendaal KJ, Wildevuur $\mathrm{CR}$. On the mechanism of platelet preservation during cardiopulmonary bypass by Aprotinin. Lancet 1988;1:644-6.

7. Havel M, Teufelsbauer $H$, Knöbl P, et al. Effect of intraoperative aprotinin administration on postoperative bleeding in patients undergoing cardiopulmonary bypass operation. J ThORAC CARDIOvASC SURG 1991;101:968-972.

8. Havel M, Griesmacher A, Weigel G, et al. Aprotinin decreases release of 6-keto-prostaglandin $F_{1 \alpha}$ and increases release of Thromboxane- $\mathrm{B}_{2}$ in cultured human umbilical vein endothelial cells. J THORAC CARDIOvaSC SURG 1992; 104:654-8.

9. Havel M, Griesmacher A, Weigel G, et al. Aprotinin increases release of von Willebrand-factor in cultured human umbilical vein endothelial cells. Surgery [In press].

10. SAS users Guide. Statistical analysis system. Cary, N. C.: SAS Institute, 1985. 